\title{
CIELAB analysis and quantitative correlation of total anthocyanin content in European and Asian plums
}

\author{
E. Rampáčková ${ }^{1}$, M. Göttingerová ${ }^{1}$, T. Kiss ${ }^{1}$, I. Ondrášek ${ }^{1}$, R. Venuta ${ }^{2}$, J. Wolf ${ }^{1}$, T. Nečas ${ }^{1}$ and S. Ercisli ${ }^{3}$ \\ ${ }^{1}$ Department of Fruit Science, Faculty of Horticulture in Lednice, Mendel University in Brno, Czech Republic \\ ${ }^{2}$ Fruit Nursery Rostislav Venuta, Kadov, Czech Republic \\ ${ }^{3}$ Department of Horticulture, Ataturk University, Agricultural Faculty, Turkey
}

\begin{abstract}
Summary
Fruits are a rich source of vitamins and antioxidants and their consumption is important for human health. Anthocyanins contribute to antioxidant characteristics in colourful fruits, especially with blue, purple and red tones of colour. The aim of this work was to study the correlation between anthocyanin content and the external colour of plums. European (Prunus domestica) and Asian (Prunus salicina) plum cultivars and inter-specific hybrids of the Japanese plum and the apricot (Prunus armeniaca) - pluots were chosen for this investigation. Results showed that total anthocyanin content in fruits ranged between 0.2 and $217.0 \mathrm{mg} \mathrm{kg}^{-1}$ fresh weight (FW) among varieties. High anthocyanin values were measured in cultivars derived from the Japanese plums 'Black Amber' and 'Black Star', however, the highest values were surprisingly measured in the pluot 'Flavorich pluot $^{\circledR}$ '. Anthocyanin values for European plum cultivar 'Čačanska rodna' corresponded to the previous scientific studies and reached the level of $77.0 \mathrm{mg} \mathrm{kg}^{-1}$ FW. The colour of the fruit was measured using the colour scale set by the Commission Internationale de L'Eclairage (CIELAB) and from chromatic parameters $L^{*}, a^{*}, b^{*}$ the chroma parameter $\left(C^{*}{ }_{a b}\right)$, hue angle $\left(h^{\circ}{ }_{a b}\right)$ and colour index of red grapes (CIRG) were calculated. Correlation of the colour parameters with the anthocyanin content in plum fruits was determined and it was found that CIRG is a suitable comparison parameter with exponential positive correlation to anthocyanin content. The present work highlights that colour parameters, especially CIRG, are a good identifier of approximate value of anthocyanin content with using founded regression function. This method could be used to obtain an overview about healthy substances of fruit without its destruction or using chemical analyses.
\end{abstract}

Keywords

anthocyanins, CIELAB, colorimetry, fruit colour, plums

\section{Introduction}

The internal and external quality of fruits is affected by various parameters. Secondary metabolites, including antioxidants, are an important quality criterion in fruits. Antioxidants are substances that protect human cells against oxidative stress, neutralize free radicals in the body and thereby slow cellular ageing. Regular consumption of fruit and vegetables rich in antioxidants reduces the risk of chronic and

\section{Significance of this study}

What is already known on this subject?

- Using CIELAB analysis to analyse many types of fruit. A correlation between anthocyanin content and colour of fruit skin.

What are the new findings?

- Variability of anthocyanin content in single cultivars of plums and difference regarding to their origin. Comparison of correlations between various chromatic parameters and total anthocyanin content in plums.

What is the expected impact on horticulture?

- Possibility of using chromatic parameters as an indicator of anthocyanin content in plums.

degenerative diseases in humans (Desmarchelier and Borel, 2017).

Depending on their origin, plums are mainly classified as European (Prunus domestica L.), Asian (Prunus salicina Lindl.) and cherry plums (Prunus cerasifera Ehrh.) (Okie and Weinberger, 1996). However, their common attribute is that their fruit is an excellent source of nutritive substances for humans (Cao et al., 1997). They are particularly known for their high antioxidant content, which was proven in many studies worldwide (Kim et al., 2003; Rop et al., 2009; Mihalanche et al., 2014; Rahaman et al., 2019; Li et al., 2019; Radović et al., 2020; Cabrera-Bañegil et al., 2020; Manzano Durán et al., 2020). Anthocyanins pose an important group of antioxidants in the fruit of plums (Rupasinghe et al., 2006; Usenik et al., 2008; Treutter et al., 2012; Tomić et al., 2019). They are phenolic substances, belonging to the subgroup of flavonoids, which are widespread in fruits and vegetables. The presence of these pigments in plums is manifested in red, blue and violet coloured fruits (Tomić et al., 2019).

Colour plays a fundamental role in consumer choices, is associated to quality and genuineness, and could be correlated with the presence of a characteristic pigments (Patsilinakos et al., 2018). Colour may be affected by many environmental factors, such as light, temperature (Lado et al., 2018), moisture, or soil type (Simon et al., 2016). Sahamishirazi et al. (2017) and Xu et al. (2011) reported that there is a negative correlation between air temperature and the concentration of phenolics in plums, including also anthocyanins. In the study from Serbia (Tomić et al., 2019), the amount of anthocyanin decreased during harvesting time in late and very late cultivars compared to early and mid-early cultivars. The colour of the fruit depends on the amount and distribution 
of anthocyanins in the fruit skin where it is generally found in higher concentration in comparison with the flesh (Cevallos-Casals et al., 2006). Sahamishirazi et al. (2017) found higher anthocyanin content in violet cultivars in comparison with other cultivars. However, those differences were not significant, which could be due to the low statistical power caused by the low number of green and yellow cultivars included in the comparison (Sahamishirazi et al., 2017). Usenik et al. (2009) studied the influence of ripeness on the accumulation of anthocyanins in plums where correlations between anthocyanin composition and colour measurements were found.

The assessment of colour differences by CIELAB analysis is often used to analyse many types of fruit. It was used to study total anthocyanin content in sweet cherries where an exponential relation between total anthocyanin content and the chromatic parameters was observed (Gonçalves et al., 2006). Shahab et al. (2020) studied content of anthocyanins in table grapes, where they found linear relation between CIRG and total anthocyanin content.

The colour of the skin of plum fruits, specifically the fruits of European and Japanese plums and pluots, was measured in relation to total anthocyanin content. The correlation between the data specifying the colour of the skin of the fruit and the measured data for total anthocyanin content in plums was subsequently determined. The CIELAB analyses were not used in many studies for measuring anthocyanins content depending on colour of plums (Usenik et al., 2009; Sahamishirazi et al., 2017). This study is focused on determination total anthocyanin content of plums planted in the Czech Republic and also on determining the significant correlation between total anthocyanin content and the colour of plums. The results could be used in future as a template to determine approximate content of anthocyanins in plums without their destruction.

\section{Materials and methods}

\section{Site of planting and plant material}

The ripe plums were harvested on the experimental land of the Faculty of Horticulture in Lednice, Mendel University in Brno (localisation $48.80^{\circ} \mathrm{N}, 16.80^{\circ} \mathrm{E}$, at an altitude of $172 \mathrm{~m}$ ). In 2019 , the average temperature was $11.5^{\circ} \mathrm{C}$, annual rainfall was $528.1 \mathrm{~mm}$ and sunlight reached a value of 1,982.9 h. During the growing period (April-September), the average temperature was $17.7^{\circ} \mathrm{C}$, rainfall was $349.0 \mathrm{~mm}$ and sunlight was $1,379.3 \mathrm{~h}$.

The plum trees were grown in a form of a free-standing pyramid on cherry plum (myrobalan) seedling rootstock, spaced $5 \times 3 \mathrm{~m}$. Four cultivars of $P$. domestica, 12 cultivars of $P$. salicina and five cultivars of pluots have been studied. Cultivars according to their origin and appropriate date of harvest that were used in this study are mentioned in Table 1.

Ten fruits were harvested at optimum maturity, which was defined when significant proportions of fruits have attained the minimum \% colour (every fruit must have the minimum percentage of its surface coloured) (Siddiq and Sultan, 2012). The harvested fruits were transported to the laboratory and analysed immediately to prevent loss of water and antioxidant activity during storage.

\section{Determination of total anthocyanin content (TAC)}

The analysis was based on a $\mathrm{pH}$ differential method, which uses changes in the colour of samples containing anthocyanins in environments of various $\mathrm{pH}$ value (Giusti and Wrolstad, 2001).
TABLE 1. Cultivars used in this study with appropriate date of harvest.

\begin{tabular}{llc}
\hline Origin & Cultivars & Date of harvest \\
\hline European plum & Althan's Gage & 14.8 \\
& Topking & 21.8 \\
& Timochanka & 3.8 \\
& Čačanska rodna & 21.8 \\
\hline Japanese plum & Shiro & 9.8 \\
& Golden Japan & 18.7 \\
& Vanier & 3.8 \\
& Ozark Premier & 27.7 \\
& Sorriso di Primavera & 9.8 \\
& Fortune & 9.8 \\
& Sussino Coco Pisa & 18.7 \\
& Crimson Glo & 12.8 \\
& Angeleno & \\
& Aphrodite & 19.8 \\
& Black Star & 9.8 \\
& Black Amber & 27.7 \\
& Flavor Queen pluot ${ }^{\circledR}$ & 12.8 \\
\hline Pluot & Dapple Dandy pluot ${ }^{\circledR}$ & 14.8 \\
& Black Giant ${ }^{\circledR}$ & 9.8 \\
& Dapple Supreme pluot ${ }^{\circledR}$ & 8.8 \\
& Flavorich pluot & 8.8 \\
& & 3.9 \\
\hline
\end{tabular}

An analytical scale was used to weigh $5 \mathrm{~g}$ of homogenized whole fruits of plum, to which $25 \mathrm{~mL}$ of $0.1 \mathrm{M} \mathrm{HCl}$ was added. After extraction $(1 \mathrm{~h})$ the solution was filtered and $0.5 \mathrm{~mL}$ was pipetted into 6 test tubes. A $2.5 \mathrm{~mL}\left(0.025 \mathrm{~mol} \mathrm{~L}^{-1}\right)$ volume of $\mathrm{KCl}$ solution of $\mathrm{pH} 1$ was pipetted into the first three testtubes and $2.5 \mathrm{~mL}\left(0.4 \mathrm{~mol} \mathrm{~L}^{-1}\right)$ solution of $\mathrm{C}_{2} \mathrm{H}_{3} \mathrm{NaO}_{2}$ of $\mathrm{pH} 4.5$ was pipetted into the remaining three test tubes. The samples were measured on a spectrophotometer SPECORD ${ }^{\circledR} 50$ Plus (Analytic Jena AG, Germany) at wavelengths of $510 \mathrm{~nm}$ and $700 \mathrm{~nm}$ and the results were expressed in $\mathrm{mg} \mathrm{kg}^{-1}$ fresh weight (FW).

\section{Colour analysis}

Colour analysis was accomplished on cleaned skin of 10 ripe fruits of each cultivar. On fruits of every cultivar the over colour was measured. Where possible, the ground colour was measured as well. The CIELAB scale is based on measuring colour in terms of standard observed and standard illuminant (Lancaster et al., 1997). The measured colour is located as a point in three-dimensional space, observed by $L^{*}, a^{*}, b^{*}$ axis. Parameter $L^{*}$ represents the lightness of the fruit, parameter $a^{*}$ represents the axis in the direction from green to red, and parameter $b^{*}$ represents the axis in the direction from blue to yellow. The parameters chroma $\left(C^{*}{ }_{a b}\right)$, hue angle $\left(h^{\circ}{ }_{\mathrm{ab}}\right)$ (Voss, 1992) and colour index of red grapes (CIRG) (Carreño et al., 1995) were also determined for the purpose of statistical evaluation. $C^{*}{ }_{\mathrm{ab}}$ indicates the purity or intensity of colour and $h^{\circ}$ ab expresses the colour nuance (Voss, 1992). The values are defined as follows: red-purple: $0^{\circ}$, yellow: $90^{\circ}$, bluish-green: $180^{\circ}$, and blue: $270^{\circ}$ (McGuire, 1992).

CIELAB parameters $\left(L^{*}, a^{*}, b^{*}\right)$ were measured directly by colorimeter CR-400 (Konica Minolta ${ }^{\circledR}$, Tokyo, Japan), equipped with D65 illuminant. The data were processed by software SpectraMagic NX Lite (Konica Minolta ${ }^{\circledR}$, Tokyo, Japan). Values were displayed with the mean \pm standard 
deviation. Cylindrical coordinates $C^{*}$ ab and $h^{\circ}$ ab were calculated from coordinates $a^{*}$ and $b^{*}$ by equation (1) and (2) (Clydesdale and Ahmed, 1978):

$$
\begin{aligned}
& C^{*}{ }_{\mathrm{ab}}=\left(a^{* 2}+b^{* 2}\right)^{1 / 2} \\
& h^{\circ}{ }_{\mathrm{ab}}=\tan ^{-1}\left(b^{*} / a^{*}\right)
\end{aligned}
$$

when $a^{*}<0$ and $b^{*}>0$, then $h_{\mathrm{ab}}^{\circ}=180^{\circ}+\tan ^{-1}\left(b^{*} / a^{*}\right) \cdot C^{*}{ }_{a b}$ denotes the purity of saturation of the colour (Voss, 1992), which means the higher is the chroma $\left(C^{*}\right.$ ab $)$ the colour is more intense. Hue angle $\left(h^{\circ}{ }_{\mathrm{ab}}\right)$ refers to the colour wheel and is measured in angles (McGuire, 1992). The colour index of red grapes (CIRG) was calculated using the formula (3) (Carreño et al., 1995):

$$
\mathrm{CIRG}=\left(180^{\circ}-h^{\circ}\right) /\left(L^{*}+C^{*}\right)
$$

For cultivars with visible ground colour, the colour difference $\Delta E_{a b}^{*}$ was calculated. Values were displayed with the mean \pm standard deviation of ten replications. Given two colours in CIELAB colour space, $\left(L^{*}{ }_{1}, a^{*}{ }_{1}, b^{*}{ }_{1}\right)$ and $\left(L^{*}{ }_{2}, a^{*}{ }_{2}, b^{*}{ }_{2}\right)$, the CIE76 colour difference formula is defined as (4):

$$
\Delta E^{*}{ }_{\mathrm{ab}}=\left(\Delta L^{* 2}+\Delta a^{* 2}+\Delta b^{* 2}\right)^{1 / 2}
$$

$\Delta E^{*}{ }_{\mathrm{ab}} \approx 2,3$ corresponds to a just noticeable difference (JND) (Sharma, 2003).

\section{Statistical analysis}

Statistical analysis was performed in Statistica 12 (TIBCO, U.S.A.) and Microsoft Excel software. Single-factor ANOVA analysis (level of significance $\alpha=0.05$ ) was used for statistical processing and the Tukey HSD test was subsequently used to evaluate the statistical significance of differences between the individually measured values (TAC and chromatic parameters $L^{*}, a^{*}, b^{*}$ ). Between colour parameters and TAC the Spearman's correlation coefficient $\rho$ was determined using Statistica 12 (TIBCO, U.S.A.) and regression function with coefficient of determination $\mathrm{R}^{2}$ was determined using Microsoft Excel.

\section{Results}

The average TAC of the studied plum fruits was $80 \pm 72 \mathrm{mg} \mathrm{kg}^{-1} \mathrm{FW}$. According to the magnitude of standard deviation the TAC in the fruit differed significantly. The results are recorded in Table 2 . The highest content was measured in the 'Flavorich pluot ${ }^{\circledR \prime}$ ' cultivar $\left(217.4 \pm 2 \mathrm{mg} \mathrm{kg}^{-1} \mathrm{FW}\right)$ and the lowest in the 'Shiro' cultivar $\left(0.2 \pm 0.1 \mathrm{mg} \mathrm{kg}^{-1} \mathrm{FW}\right)$. The average TAC value in European plums was $46.5 \mathrm{mg} \mathrm{kg}^{-1}$ FW, with the 'Čačanska rodna' cultivar achieving the highest value $\left(77 \pm 1 \mathrm{mg} \mathrm{kg}^{-1} \mathrm{FW}\right)$. The average TAC value measured in Japanese plum cultivars was $72.1 \mathrm{mg} \mathrm{kg}^{-1} \mathrm{FW}$, with the 'Black Amber' (196.7 $\pm 2 \mathrm{mg} \mathrm{kg}^{-1} \mathrm{FW}$ ) and 'Black Star' $\left(153.0 \pm 1 \mathrm{mg} \mathrm{kg}^{-1} \mathrm{FW}\right)$ cultivars achieving the highest values.

There was a noticeable difference between the fruit skin colours of tested cultivars. Japanese plum cultivars 'Shiro' and 'Golden Japan' and pluot 'Flavor Queen pluot ${ }^{\circledR \prime}$ had yellow skin and flesh (Figure 1). Interesting cultivar with light red skin and red flesh was the Japanese plum 'Vanier' and with green-redish skin and dark red flesh the pluot 'Dapple Supreme pluot ${ }^{\circledR}$. The darkest skin had Japanese plum 'Black Star' and pluots 'Black Giant ${ }^{\circledR \prime}$ and 'Flavorich pluot ${ }^{\circledR \prime}$ (Figure 1). All cultivars of European plum had typical dark skin (Figure 2) and light green-yellowish flesh.

Chromatic parameters of recorded over colours are shown in Table 3. Lightness $\left(L^{*}\right)$ values ranged between 63.25 ('Flavor Queen pluot ${ }^{{ }^{\prime}}$ ) and 22.10 ('Black Star'). The
TABLE 2. Total anthocyanin content in plum cultivars. The

\begin{tabular}{|c|c|c|}
\hline Origin & Cultivars & Anthocyanins $\left(\mathrm{mg} \mathrm{kg}^{-1}\right)$ \\
\hline \multirow[t]{4}{*}{ European plum } & Althan's Gage & $4.8 \pm 0.2^{a}$ \\
\hline & Topking & $47 \pm 3$ de \\
\hline & Timochanka & $57.2 \pm 0.4^{f}$ \\
\hline & Čačanska rodna & $77 \pm 1^{\mathrm{h}}$ \\
\hline \multirow[t]{12}{*}{ Japanese plum } & Shiro & $0.2 \pm 0.1 \mathrm{a}$ \\
\hline & Golden Japan & $0.9 \pm 0.3^{a}$ \\
\hline & Vanier & $12.7 \pm 0.8^{b}$ \\
\hline & Ozark Premier & $15.5 \pm 0.6^{b}$ \\
\hline & Sorriso di Primavera & $34.0 \pm 0.2^{c}$ \\
\hline & Fortune & $46.1 \pm 0.3^{d}$ \\
\hline & Sussino Coco Pisa & $50.9 \pm 0.3$ de \\
\hline & Crimson Glo & $86.3 \pm 0.6^{i}$ \\
\hline & Angeleno ${ }^{\circledR}$ & $108 \pm 2^{j}$ \\
\hline & Aphrodite & $147.7 \pm 0.8^{k}$ \\
\hline & Black Star & $153 \pm 1 k$ \\
\hline & Black Amber & $197 \pm 2^{\prime}$ \\
\hline \multirow[t]{5}{*}{ Pluot } & Flavor Queen pluot ${ }^{\circledR}$ & $0.5 \pm 0.1^{a}$ \\
\hline & Dapple Dandy pluot ${ }^{\circledR}$ & $51.9 \pm 0.7$ ef \\
\hline & Black Giant ${ }^{\circledR}$ & $63.8 \pm 0.49$ \\
\hline & Dapple Supreme pluot ${ }^{\circledR}$ & $148.1 \pm 0.8^{k}$ \\
\hline & Flavorich pluot ${ }^{\circledR}$ & $217 \pm 2 \mathrm{~m}$ \\
\hline
\end{tabular}
data is displayed with the mean \pm standard deviation of three replications. Superscripts a...m refer to the grouping based on Tukey HSD test.

highest $L^{*}$ values had the cultivars with yellow coloured fruits, i.e., 'Flavor Queen pluot ${ }^{\circledR}$ ', and Japanese plum cultivars 'Golden Japan' and 'Shiro'. On the contrary, the lowest $L^{*}$ values were measured in fruits from Japanese plum cultivars with dark fruits, i.e., 'Black Star', 'Black Giant ${ }^{\circledR \prime}$ and from the pluot 'Flavorich pluot ${ }^{\circledR}$ '. The average $L^{*}$ in European plum cultivars reached values of 26.98, in Japanese cultivars 32.09, and in pluots 34.83 .

Values $a^{*}$ and $b^{*}$ are inappropriate parameters for comparison of cultivars, because one coordinate does not correctly describe the real colour of the fruit skin. However, they are incorporated in the calculation of $C^{*}{ }_{\text {ab }}$ and $h^{\circ}{ }_{\text {ab }}$ parameters, which describe the measured colours better. The value $C^{*}{ }_{\text {ab }}$ ranged from 5.48 ('Black Star') to 45.37 ('Golden Japan'). The average value of $C^{*}$ ab for European plums was 15.67, 18.17 for Japanese plums and 29.03 for pluots.

Parameter $h^{\circ}{ }_{\text {ab }}$ ranged most frequently in the quadrant from $0^{\circ}$ to $90^{\circ}$, i.e., most cultivars rated a red-yellow colour. The cultivars 'Topking', 'Čačanska rodna' and 'Black Star' came closest to red $\left(h^{\circ}{ }_{\mathrm{ab}} \cong 0^{\circ}\right)$. Cultivars with fruits of a shade of yellow $\left(h^{\circ}{ }^{\circ} \cong 90^{\circ}\right)$ included 'Golden Japan', 'Flavor Queen

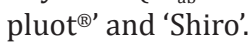

CIRG values, calculated from chromatic parameters $L^{*}, C^{*}{ }_{a b}$ and $h^{\circ}$ ab, were determined in the range from 0.81 ('Flavor Queen pluot ${ }^{\circledR}$ ) to 6.26 ('Black Star') (Figure 1). The lowest CIRG values were calculated for the cultivars with yellow fruits 'Flavor Queen pluot ${ }^{\circledR}$ ' and Japanese plums 'Golden Japan' and 'Shiro', and the highest were calculated for fruits of Japanese plums 'Black Star', 'Black Giant ${ }^{\circledR}$, the pluot 'Flavorich pluot ${ }^{\circledR \prime}$ and European plum 'Čačanska rodna'.

The skin ground colour was visible only at European plum 'Althan's Gage', Japanese plums 'Vanier, 'Ozark Premier', 'Black Amber', and pluots 'Flavor Queen pluot ${ }^{\circledR}$ ', 'Dapple 
Supreme pluot ${ }^{\Theta^{\prime}}$ (Table 4) and the ground and over colour difference $\Delta E$ (Figure 2) was calculated from their chromatic parameters (Tables 3 and 4). The lowest value was calculated for 'Flavor Queen pluot ${ }^{\circledR \prime}$ ' (12.43), next cultivars were 'Dapple Supreme pluot ${ }^{\circledR \prime}$ (18.75), 'Althan's Gage' (38.03), 'Black Amber' (41.15), 'Vanier' (49.18) and the highest value was calculated for 'Ozark Premier' (53.00). All of them had noticeable different ground and over colours, which is determined by higher value than the JND ( $\Delta E^{*}{ }_{\mathrm{ab}} \approx 2.3$ ) (Sharma, 2003).

Main task of this study was to find correlation between TAC and chromatic parameters. All correlations of TAC and chromatic parameters except for $a^{*}$ and TAC showed significant correlations (Table 4). The regression functions were determined in correlated relationships (Table 5; Figure 3). Most of these functions were decreasing and exponential. Correlation was assessed by Spearman's correlation coeffi-

TABLE 3. The measured chromatic parameters $L^{*}, a^{*}, b^{*}$ for the over colour of fruits of plum cultivars. Values are displayed with the mean \pm standard deviation of ten replications for each cultivar. Superscripts a...j refer to the grouping based on Tukey HSD test. The parameters $C^{*}{ }_{a b}, h^{\circ}{ }_{a b}$, CIRG were counted according to equations (1), (2), (3).

\begin{tabular}{|c|c|c|c|c|c|c|c|}
\hline Origin & Cultivars & $L^{*}$ & $a^{*}$ & $b^{*}$ & $C_{\mathrm{ab}}^{*}$ & $h^{\circ}{ }_{a b}$ & CIRG \\
\hline \multirow{4}{*}{ European plum } & Althan's Gage & $33.6 \pm 0.6$ de & $17.8 \pm 0.9$ efg & $8.5 \pm 0.6 \mathrm{de}$ & 19.77 & 25.61 & 2.90 \\
\hline & Čačanska rodna & $24.7 \pm 0.6 \mathrm{abc}$ & $8.2 \pm 0.5^{c}$ & $0.0 \pm 0.4^{a}$ & 8.23 & 359.90 & 5.47 \\
\hline & Timochanka & $23.2 \pm 0.5 \mathrm{ab}$ & $9 \pm 1^{c}$ & $1.3 \pm 0.4 \mathrm{ab}$ & 8.83 & 8.53 & 5.36 \\
\hline & Topking & $26 \pm 1$ bc & $8.0 \pm 0.8^{c}$ & $0.0 \pm 0.6^{a}$ & 8.05 & 359.98 & 5.28 \\
\hline \multirow[t]{12}{*}{ Japanese plum } & Angeleno ${ }^{\circledR}$ & $26.0 \pm 0.4$ bc & $10 \pm 1^{\text {cd }}$ & $2.1 \pm 0.5 \mathrm{ab}$ & 19.83 & 12.18 & 4.69 \\
\hline & Aphrodite & $24.4 \pm 0.4 \mathrm{abc}$ & $17.4 \pm 0.9 \mathrm{efg}$ & $3.0 \pm 0.4 a b c$ & 17.61 & 9.71 & 4.05 \\
\hline & Black Amber & $27.4 \pm 0.6^{c}$ & $14 \pm 2^{\text {de }}$ & $4.9 \pm 0.9 \mathrm{bcd}$ & 15.18 & 18.64 & 3.78 \\
\hline & Black Star & $22.1 \pm 0.3^{a}$ & $6.1 \pm 0.8 \mathrm{bc}$ & $0.3 \pm 0.1^{a}$ & 6.12 & 3.19 & 6.23 \\
\hline & Crimson Glo & $26.1 \pm 0.3 b c$ & $8.5 \pm 0.9 c$ & $2.1 \pm 0.4 \mathrm{abc}$ & 8.71 & 14.06 & 4.76 \\
\hline & Fortune & $26.3 \pm 0.4 \mathrm{bc}$ & $23 \pm 1^{\mathrm{gh}}$ & $5.7 \pm 0.6^{c d}$ & 23.35 & 14.20 & 3.34 \\
\hline & Golden Japan & $60.2 \pm 0.6^{g}$ & $-1.3 \pm 0.8^{a}$ & $45.4 \pm 0.7^{i}$ & 45.37 & 91.70 & 2.54 \\
\hline & Ozark Premier & $27.6 \pm 0.5^{\circ}$ & $21 \pm 1^{\mathrm{fg}}$ & $5.7 \pm 0.6^{\mathrm{cd}}$ & 21.39 & 15.43 & 3.36 \\
\hline & Shiro & $49 \pm 1^{f}$ & $1.6 \pm 0.5^{a b}$ & $35 \pm 2^{h}$ & 35.10 & 87.45 & 1.10 \\
\hline & Sorriso di Primavera & $31 \pm 1^{d}$ & $22 \pm 2^{g h}$ & $12 \pm 1$ ef & 25.13 & 28.69 & 2.68 \\
\hline & Susino Coco Pisa & $27.6 \pm 0.4^{c}$ & $16 \pm 2$ ef & $3.9 \pm 0.7 \mathrm{abc}$ & 16.28 & 13.93 & 3.79 \\
\hline & Vanier & $36 \pm 2 \mathrm{e}$ & $33 \pm 1 j$ & $21 \pm 2^{g}$ & 38.89 & 31.92 & 1.99 \\
\hline \multirow[t]{5}{*}{ Pluot } & Black Giant ${ }^{\circledR}$ & $23.6 \pm 0.2^{a b}$ & $5.5 \pm 0.5 \mathrm{bc}$ & $0.5 \pm 0.1^{a}$ & 5.49 & 4.49 & 6.02 \\
\hline & Dapple Dandy pluot & $27.5 \pm 0.6^{c}$ & $27 \pm 1^{\mathrm{hi}}$ & $8.4 \pm 0.7$ de & 28.16 & 17.25 & 2.92 \\
\hline & Dapple Supreme pluot ${ }^{\circledR}$ & $36.0 \pm 0.8^{e}$ & $29 \pm 1^{i j}$ & $15.7 \pm 0.5^{f}$ & 33.08 & 28.25 & 2.19 \\
\hline & Flavor Queen pluot ${ }^{\circledR}$ & $63.2 \pm 0.5 \mathrm{~g}$ & $-1.7 \pm 0.9 \mathrm{a}$ & $45 \pm 1^{i}$ & 44.71 & 92.20 & 2.48 \\
\hline & Flavorich pluot ${ }^{\circledR}$ & $23.5 \pm 0.5^{\mathrm{ab}}$ & $5.6 \pm 0.3^{b c}$ & $0.9 \pm 0.2 \mathrm{ab}$ & 5.72 & 9.49 & 5.84 \\
\hline
\end{tabular}

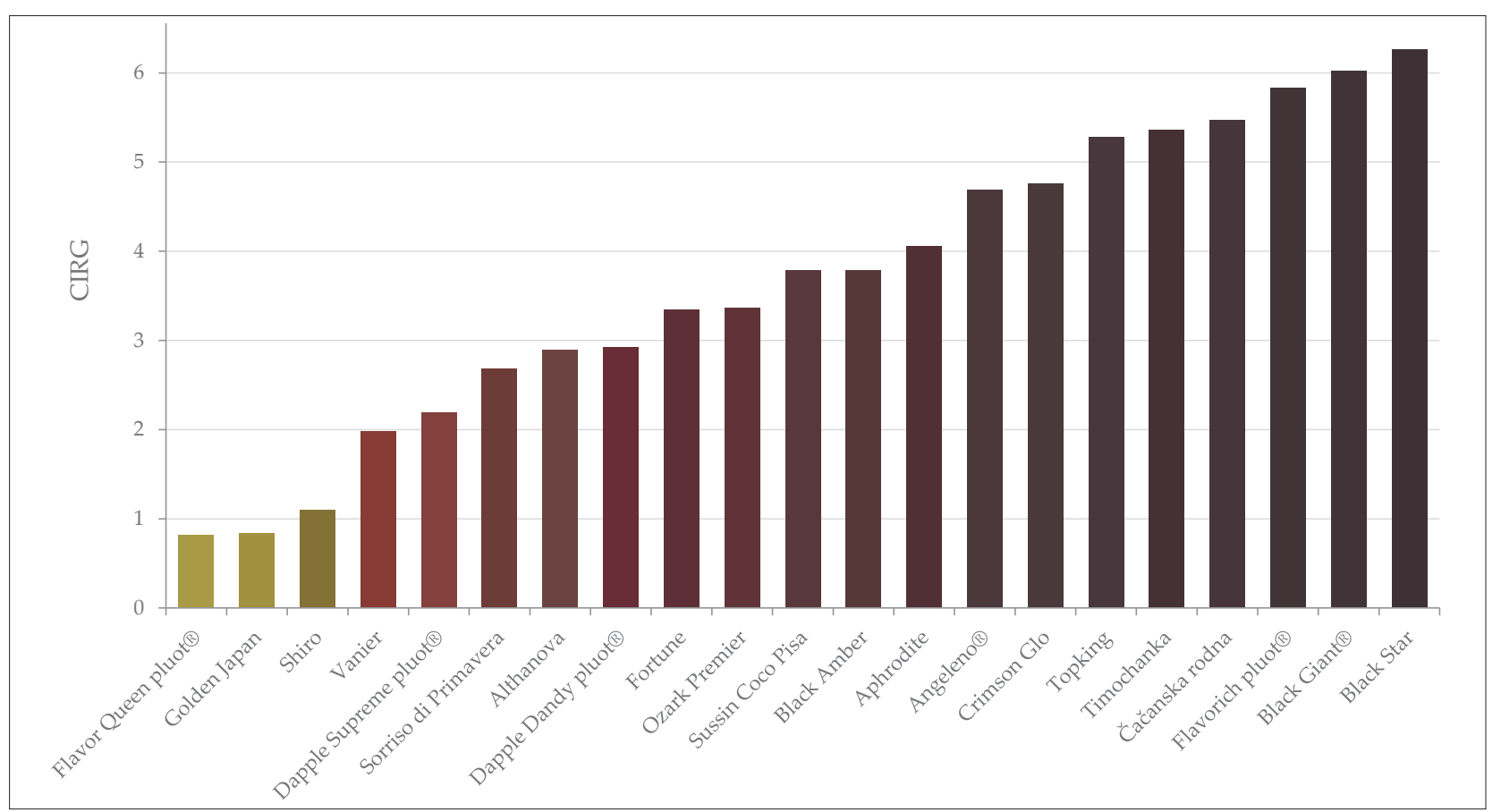

FIGURE 1. Graphic portrayal of CIRG in all cultivars and their actual colours, according to measured values of $L^{*}, a^{*}$, and $b^{*}$. 
cient $\rho$ (Table 5). A high TAC value was measured at 'Dapple Supreme pluot ${ }^{\circledR \prime}$ cultivar, however, due to its greenish skin but reddish flesh (increasing the TAC), it did not fit in correlation patterns with other cultivars with dark skin and lighter flesh. This cultivar was therefore not included in further calculations of correlation between TAC and chromatic parameters.

Highly significant negative correlation $(\rho=-0.8451$, Table 5) was calculated between TAC and $L^{*}$ indicating that darker plums had higher TAC (Figure 3a). Similarly, high negative correlation $(\rho=-0.7714$, Table 5$)$ between TAC and chromatic parameter $b^{*}$ was calculated as well (Figure $3 \mathrm{~b})$. The lowest value $b^{*}=-0.003$ was recorded for European plum cultivars 'Topking' and 'Čačanska rodna' which contained the most of the blue pigment. The highest value of $b^{*}=45.4$ was recorded at Japanese plum cultivar 'Golden Japan', and high values were also recorded for 'Flavor Queen pluot $^{\circledR '}$ and 'Shiro'. Obviously, these typically yellow coloured cultivars had the lowest TAC. On the contrary, no correlation was found between parameter $a^{*}$ and TAC (Table 5) because plums in our study were mostly bluish (with high TAC) or yellowish (with low TAC) (Figure 3c).

All counted chromatic parameters $C^{*}{ }_{\mathrm{ab}}, h^{*}{ }_{\mathrm{ab}}$ and CIRG had significant correlation with TAC. The correlation coefficient $\rho$ between TAC and $C^{*}{ }_{\text {ab }}$ was -0.8226 (Table 5; Figure $3 \mathrm{~d}$ ) and between $h^{*}{ }_{\mathrm{ab}}$ and TAC -0.7188 (Table 5; Figure 3e). It means that TAC of plums is related to the colour shade. Cultivars with the highest TAC had values of $h^{*}{ }_{\mathrm{ab}} \cong 0$, which corresponds to the red-purple colour.

The highest and the only positive correlation with $\rho=0.8526$ was calculated between TAC and CIRG (Table 5; Figure 3f). Thus, the CIRG showed to be an applicable chromatic parameter to reflect TAC in plum cultivars.

\section{Discussion}

TAC in plum fruits was investigated in several scientific studies. In the work of Usenik et al. (2009), the average TAC of four plum cultivars was $110 \mathrm{mg} \mathrm{kg}^{-1} \mathrm{FW}$. Treutter et al. (2012) established an average TAC value of $65 \mathrm{mg} \mathrm{kg}^{-1}$ FW from analysed 28 plum cultivars. Tomás-Barberán et al. (2001) investigated the phenolic compounds content of plums skin and the average value of total anthocyanin content for four ripe fruits was $677 \mathrm{mg} \mathrm{kg}^{-1} \mathrm{FW}$, the values for flesh was much lower ( $5 \mathrm{mg} \mathrm{kg}^{-1} \mathrm{FW}$ to $28 \mathrm{mg} \mathrm{kg}^{-1} \mathrm{FW}$ ). Miletić et al. (2012) dealed with phenolic content of plum 'Stanley' during ripening and the TAC values ranged from 50 to 570 mg CGE kg-1 FW, where CGE means cyaniding-3-glucoside equivalents, which was used as an internal standard for quantification. Sahamishirazi et al. (2017) got inspired by this study and he found that values of TAC in plums ranged from 11 to 2,168 mg CGE $\mathrm{kg}^{-1}$ FW. Cömert et al. (2020) determined TAC in plums $190 \mathrm{mg} \mathrm{kg}^{-1} \mathrm{FW}$ and in comparison to other species of fruit it was classified as medium-antioxidant. The classification was based on potential contributions to meet the recommended daily TAC requirement (Cömert et al., 2020). The average TAC value in this study was $80 \mathrm{mg} \mathrm{kg}^{-1}$ FW (ranged from 0.2 to $217 \mathrm{mg} \mathrm{kg}^{-1} \mathrm{FW}$ ). Radović et al. (2020) found that TAC in European plum ranged from 187 to $733 \mathrm{mg} \mathrm{CGE} \mathrm{kg}^{-1} \mathrm{FW}$. According to Usenik et al. (2009) the TAC in the cultivar 'Čačanska rodna' was $74 \mathrm{mg} \mathrm{kg}^{-1} \mathrm{FW}$; the same values were also found in a study by Tomić et al. (2019) and these values correspond to the TAC values measured in this work (77 $\mathrm{mg} \mathrm{kg}^{-1} \mathrm{FW}$ ), but the results do not correspond to the TAC mentioned in the study of Radovic et al. (2020)

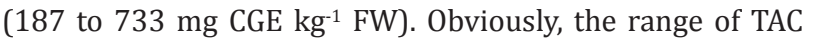
values in plums is very broad and depends on the choice of

TABLE 4. The measured chromatic parameters $L^{*}, a^{*}, b^{*}$ for the ground colour of fruits of plum cultivars with noticeable ground colour. Values are displayed with the mean \pm standard deviation of ten replications for each cultivar. Superscripts a...d refer to the grouping based on Tukey HSD test.

\begin{tabular}{|c|c|c|c|c|}
\hline Origin & Cultivars & $L^{*}$ & $a^{*}$ & $b^{*}$ \\
\hline European plum & Althan's Gage & $53.1 \pm 0.9 b$ & $-5 \pm 1 \mathrm{ab}$ & $32 \pm 1^{b}$ \\
\hline \multirow[t]{3}{*}{ Japanese plum } & Black Amber & $56 \pm 2$ bc & $-1 \pm 4^{b}$ & $31 \pm 2^{b}$ \\
\hline & Ozark Premier & $56 \pm 1 \mathrm{bc}$ & $-5 \pm 1 \mathrm{ab}$ & $42 \pm 2^{\mathrm{cd}}$ \\
\hline & Vanier & $57.9 \pm 0.9 d$ & $-3 \pm 1^{b}$ & $45 \pm 1^{d}$ \\
\hline \multirow[t]{2}{*}{ Pluot } & Dapple supreme pluot ${ }^{\circledR}$ & $44.3 \pm 0.7^{a}$ & $14 \pm 1^{c}$ & $23.4 \pm 0.7^{a}$ \\
\hline & Flavor Queen pluot ${ }^{\circledR}$ & $57.3 \pm 0.8^{d}$ & $-1.0 \pm 0.6^{a}$ & $37.5 \pm 0.6^{c}$ \\
\hline
\end{tabular}

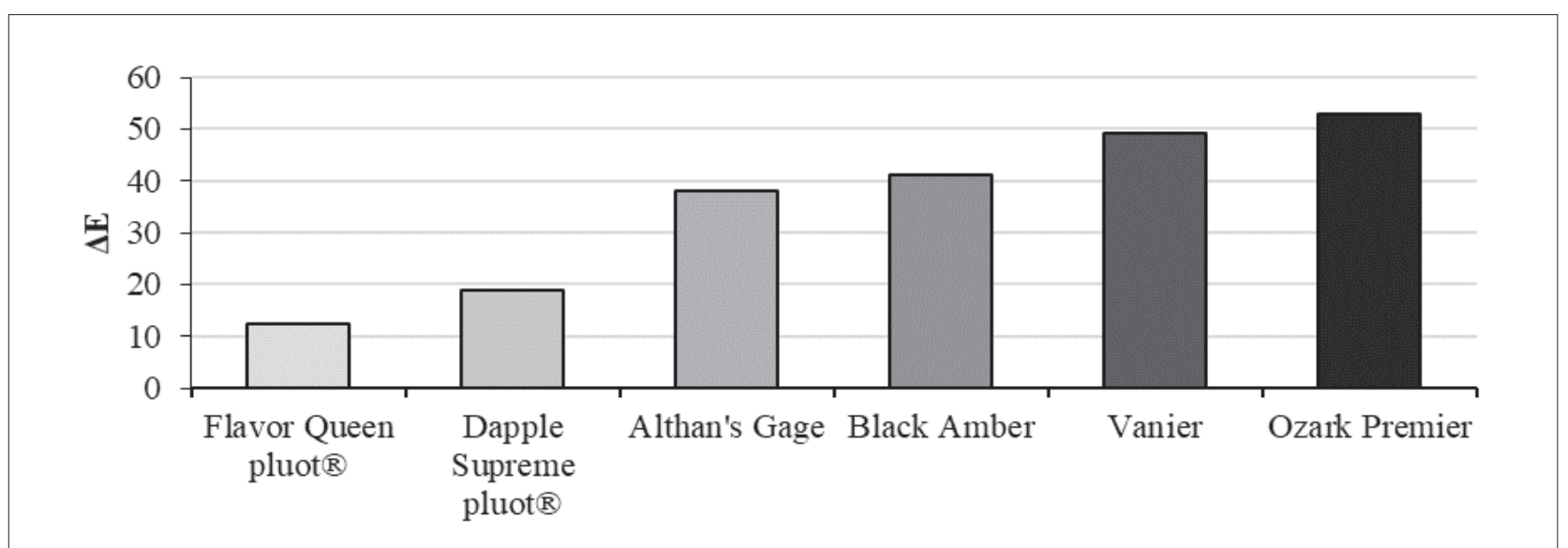

FigurE 2. The colour difference $\Delta E$ between ground and over colour of fruits of plum cultivars with visible ground colour, counted according to equation (4). 
examined cultivars. Differences in measurements can result when variously coloured fruits are used. Treutter et al. (2012) found that for yellow cultivars lower TAC was measured than for violet and dark blue cultivars, with the difference of $223 \mathrm{mg} \mathrm{kg}^{-1} \mathrm{FW}$ between the lightest and the darkest fruited cultivars. In our study the difference was 216.8 $\mathrm{mg} \mathrm{kg}^{-1} \mathrm{FW}$. Furthermore, it is known that the distribution of anthocyanins in the fruit is unequal. Radovic et al. (2020) claim anthocyanins are only present in the fruit skin in European plum fruit. Cevallos-Casals et al. (2006) mention higher anthocyanin content in the skins of plums compared to their flesh, which corresponds with the results of Tomás-Barberán et al. (2001). However, this would probably not be true for cultivars like ‘Dapple Supreme pluot ${ }^{\circledR ’}$ which is distinguished by greenish skin and dark red flesh, or 'Vanier', with red skin and red flesh, where the flesh contains probably higher TAC compared to other cultivars with lighter flesh.

Previously, some studies focused on finding correlation between TAC in plums and chromatic parameters (McGuire, 1992; Gonçalves et al., 2007; Usenik et al., 2009). McGuire

TABLE 5. Regression function $y$, coefficient of determination $R^{2}$, Spearman's correlation coefficient $\rho$ and p-values ( $\mathrm{p}$-value $\leq 0.001$ indicated as ${ }^{* * *}$ ) for individual relationships between TAC and chromatic parameters.

\begin{tabular}{llccc}
\hline & Regression function & $\mathrm{R}^{2}$ & $\rho$ & $\mathrm{p}$-value \\
\hline$L^{*}$ & $\mathrm{y}=3840.7 \mathrm{e}^{-0.155 x}$ & 0.8272 & -0.8451 & $3.010^{-6^{* * *}}$ \\
$a^{*}$ & - & - & -0.0647 & $7.910^{-1}$ \\
$b^{*}$ & $\mathrm{y}=108.2 \mathrm{e}^{-0.127 x}$ & 0.8219 & -0.7714 & $6.810^{-5 * * *}$ \\
$C^{*}{ }^{*}$ & $\mathrm{y}=369.9 \mathrm{e}^{-0.129 x}$ & 0.6833 & -0.8226 & $9.010^{-6^{* * *}}$ \\
$h^{\circ}$ & $\mathrm{y}=143.1 \mathrm{e}^{-0.063 x}$ & 0.8419 & -0.7188 & $3.610^{-4 * * *}$ \\
$\mathrm{CIRG}$ & $\mathrm{y}=0.892 \mathrm{x}^{2.969}$ & 0.8410 & 0.8526 & $2.010^{-6 * * *}$ \\
\hline
\end{tabular}

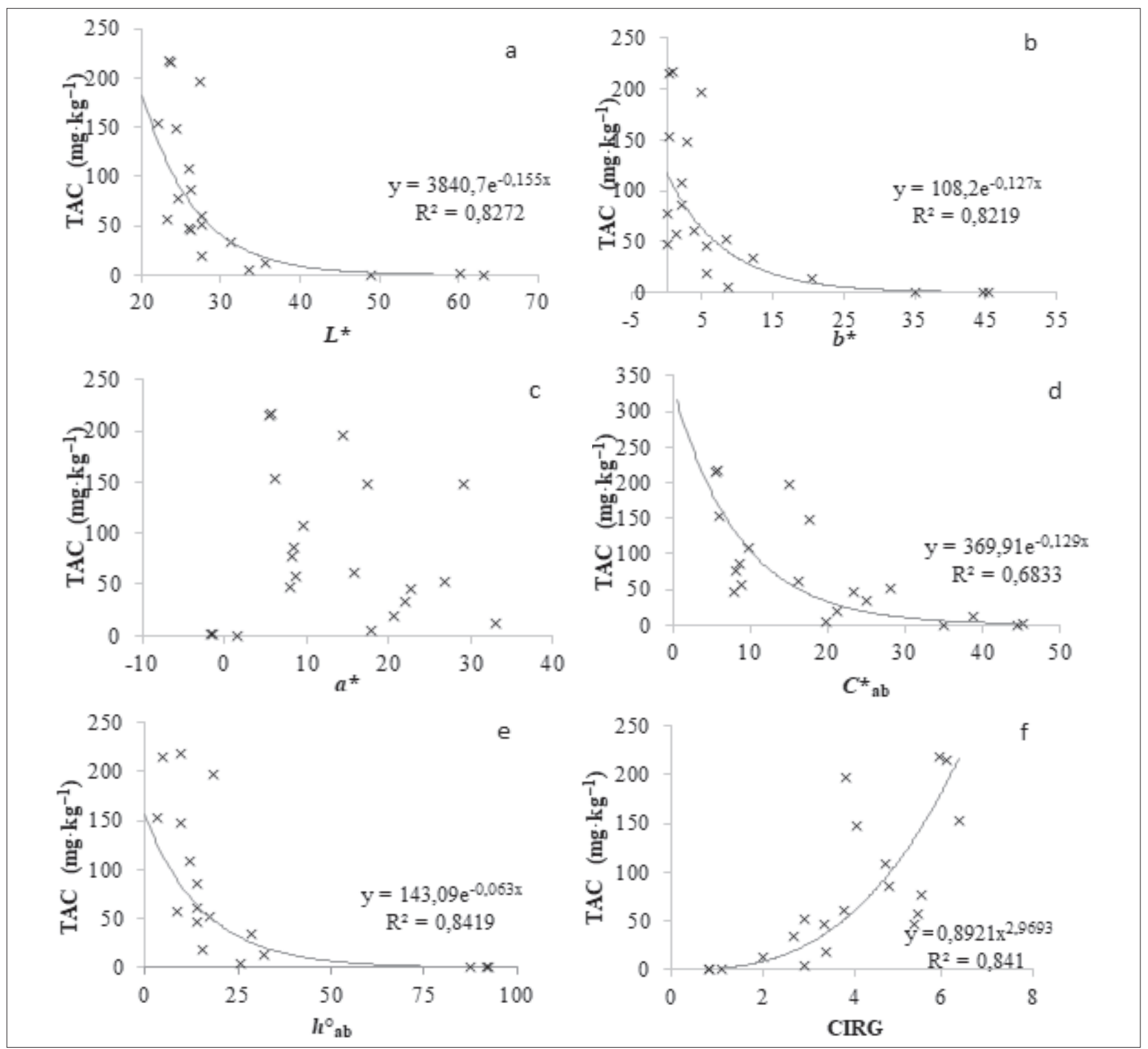

FIGURE 3. Relationships between total anthocyanins content (TAC) and chromatic parameters of the plum cultivars. 
(1992) and Gonçalves et al. (2007) found that better correlation characteristics are obtained between $h^{\circ}{ }_{\mathrm{ab}}, C^{*}{ }_{\mathrm{ab}}$ and pigment concentrations than when pigment concentrations are compared directly with the $L^{*}, a^{*}$ and $b^{*}$. In our study, significant negative correlation $(\rho=-0.8226)$ was found between $C^{*}{ }_{\text {ab }}$ and TAC (Table 5; Figure $3 \mathrm{~d}$ ) which corresponded to the results of McGuire (1992) and Gonçalves et al. (2007). Thus, the $C^{*}{ }_{a b}$ is a good indicator factor of TAC in plum cultivars used in our study. However, the lowest but still significant negative correlation was found between $h^{\circ}{ }_{\mathrm{ab}}$ and TAC $(\rho=$ -0.7188) (Table 5; Figure 3e). Usenik et al. (2009) found that the levels of TAC were weakly correlated (mainly not significantly) with colour parameters $h^{\circ}{ }_{\mathrm{ab}}$ and $C^{*}{ }_{\mathrm{ab}}$, but their results do not confirm the findings of McGuire (1992) and Gonçalves et al. (2007). Usenik et al. (2009) then considered that the correlation between pigment concentration and $L^{*}, a^{*}$ and $b^{*}$ parameters is more reliable. In our study TAC of plums decreased exponentially depending to the increase of $L^{*}$ and $b^{*}$ (Figure 3). Similarly, as with Usenik et al. (2009), reliable correlation was found in our study between $L^{*}$ and TAC, and $b^{*}$ and TAC (Figure 3a, b).

No correlation was found between parameter $a^{*}$ and TAC in our study, as the anthocyanin pigments in plums are mostly blue or purple (Figure 3c). Usenik et al. (2009) found correlation between TAC and $a^{*}$ for reddish cultivars. This correlates to Gonçalves et al. (2007) who studied TAC in sweet cherry (Prunus avium L.) and determined the strongest correlation coefficient between $a^{*}$ (redness) and cyanidin 3-rutinoside.

It was proven that there is a positive correlation between TAC and CIRG $(\rho=0.8526)$. This result confirmed the results of Carreño et al. (1995) and Shahab et al. (2020), who considered CIRG as suitable to distinguish sample groups of fruits with dark violet colour. CIRG of the cultivar 'Čačanska rodna' (4.04) in the study of Usenik et al. (2009) does not correspond to the results of this study, where 'Čačanska rodna' had one of the highest CIRG values (5.47).

\section{Conclusion}

The colour of the fruit plays a crucial role in attractiveness for the consumer. The results of this study summarise the correlation between the skin colour of plum fruits and their anthocyanin content. Of the measured chromatic parameters, the highest correlation was determined for parameter CIRG, where the anthocyanin content exponentially increased with the CIRG value, with a correlation coefficient of $\rho=0.8526$. This parameter was initially proposed as a parameter for the colour of red grapes but can be used concerning different fruit in relation to TAC. Significant negative correlation to TAC was observed for parameter $L^{*}$ (with $\rho=-0.8451$ ) and $b^{*}$ (with $\rho=-0.7714$ ), with the assumption that darker fruit contained more anthocyanins which are distinguished by their blue-purple colour. On the contrary, there was no correlation between chromatic parameter $a^{*}$ and TAC. From calculated parameters, significant negative correlation to TAC had the chroma $\left(C^{*}{ }_{\mathrm{ab}}, \rho=-0.8226\right)$ which characterizes the intensity of colour. From the tested cultivars, the cultivar 'Dapple Supreme pluot ${ }^{\circledR '}$ deviated from the established correlation reliance, which is attributed to the dark red colour of its flesh. Thus, the correlations found in this study do not correspond to this cultivar. Representatives of European plum cultivars had a surprisingly low TAC with regard to their skin colour. Various TAC values and colours were established for Japanese plum cultivars. Using the correlation relations, it can be determined an approximate value of total antho- cyanin content in plum fruits individually without destructions of fruit only with colour measuring. According to our results, the best chromatic parameter for TAC finding was CIRG, where the correlation coefficient was significant and positive, but the properties of plum flesh must be considered.

\section{Acknowledgment}

These results were obtained with the support of project NAZV/QK1910137 funded by the Ministry of Agriculture of the Czech Republic. Laboratory equipment was acquired under project CZ.02.1.01/0.0/0.0/16_017/0002334 - Research infrastructure for young scientists.

\section{References}

Cabrera-Bañegil, M., Lavado Rodas, N., Prieto Losada, M.H., Blanco Cipollone, F., Moñino Espino, M.J., Muñoz De La Peña, A., DuránMerás, I., and Ahmed, Z. (2020). Evolution of polyphenols content in plum fruits (Prunus salicina) with harvesting time by secondorder excitation-emission fluorescence multivariate calibration. Microchem. J. 158. https://doi:10.1016/j.microc.2020.105299.

Cao, G., Sofic, E., Prior, R.L., Kramarova, D., Sengee, Z., Beceanu, D., and Dommes, J. (1997). Antioxidant and prooxidant behavior of flavonoids: Structure-activity relationships. Free Radical Biol. Med. 22(5), 749-760. https//doi.org/10.1016/S0891-5849(96)00351-6.

Carreño, J., Martínez, A., Almela, L., and Fernández-López, J.A. (1995). Proposal of an index for the objective evaluation of the colour of red table grapes. Food Res. Int. 28(4), 373-377. https//doi. org/10.1016/0963-9969(95)00008-A.

Cevallos-Casals, B.A., Byrne, D., Okie, W.R., Cisneros-Zevallos, L., and Lu, J. (2006). Selecting new peach and plum genotypes rich in phenolic compounds and enhanced functional properties. Food Chem. 96(2), 273-280. https//doi.org/10.1016/j.foodchem.2005.02.032.

Clydesdale, F.M., and Ahmed, E.M. (1978). Colorimetry - Methodology and applications. Crit. Rev. Food Sci. Nutr. 10(3), 243-301.

Cömert, E.D., Mogol, B.A., and Gökmen, V. (2020). Relationship between color and antioxidant capacity of fruits and vegetables. Current Res. Food Sci. 2, 1-10. https//doi:10.1016/j.crfs. 2019.11.001.

Desmachelier, C., and Borel, P. (2017). Overview of carotenoid bioavailability determinants: From dietary factors to host genetic variations. Trends Food Sci. Technol. 69, 270-280.

Giusti, M., and Wrolstad, R. (2001). Characterization and measurement of anthocyanins by UV-visible spectroscopy. Current Protocols in Food Analytical Chemistry (Hoboken, NJ, U.S.A.: John Wiley). ISBN 0471142913.

Gonçalves, B., Silva, A.P., Moutinho-Pereira, J., Bacelar, E., Rosa, E., and Meyer, A.S. (2007). Effect of ripeness and postharvest storage on the evolution of colour and anthocyanins in cherries (Prunus avium L.). Food Chem. 103(3), 976-984. https//doi.org/10.1016/j. foodchem.2006.08.039.

Kim, D., Jeong, S.W., Lee, C.Y., Niculaua, M., Filimon, R., Beceanu, D., and Dommes, J. (2003). Antioxidant capacity of phenolic phytochemicals from various cultivars of plums. Food Chem. 81(3), 321-326. https// doi.org/10.1016/S0308-8146(02)00423-5.

Lado, J., Gambetta, G., Zacarias, L., Kramarova, D., Sengee, Z., Beceanu, D., and Dommes, J. (2018). Key determinants of citrus fruit quality: Metabolites and main changes during maturation. Sci. Hortic. 233(5), 238-248. https//doi.org/10.1016/j.scienta.2018.01.055.

Lancaster, J.E., Lister, C.E., Reay, P.F., and Triggs, C.M. (1997). Influence of pigment composition on skin color in a wide range of fruit and vegetables. J. Am. Soc. Hortic. Sci. 122(4), 594-598. https// doi.org/10.21273/JASHS.122.4.594. 
Li, Q., Chang, X.-X., Wang, H., Brennan, C.S., and Xin-Bo Guo (2019). Phytochemicals accumulation in Sanhua plum (Prunus salicina L.) during fruit development and their potential use as antioxidants. J. Agric. Food Chem. 67, 2459-2466. https//doi.org/10.1021/acs. jafc.8b05087.

Manzano Durán, R., Sánchez, J.E.F., Velardo-Micharet, B., and Gómez, M.J.R. (2020). Multivariate optimization of ultrasoundassisted extraction for the determination of phenolic compounds in plums (Prunus salicina Lindl.) by high-performance liquid chromatography (HPLC). Instrum. Sci. Technol. 48, 113-127. https//10.1080/10739149.2019.1662438.

McGuire, R.G. (1992). Reporting of objective colour measurements. HortScience 27(12), 1254-1255.

Mihalache, A., Tabart, C.J., Kevers, C., Niculaua, M., Filimon, R., Beceanu, D., and Dommes, J. (2014). Antioxidant potential of different plum cultivars during storage. Food Chem. 146(3), 485-491. https// doi.org/10.1016/j.foodchem.2013.09.072.

Miletić, N., Popović, B., Mitrović, O., and Kandić, M. (2012). Phenolic content and antioxidant capacity of fruits of plum cv. 'Stanley' (Prunus domestica L.) as influenced by maturity stage and on-tree ripening. Austral. J. Crop Sci. 6(4), 681-687.

Okie, W.R., and Weinberger, J.H. (1996). Plums. Fruit Breeding, Vol. I., Tree and Tropical Fruits, J. Janick, and J.N. Moore, eds. (New York: Wiley), p. 559-608. ISBN 0471126691.

Patsilinakos, A., Ragno, R., Carradori, S., Petralito, S., and Cesa, S. (2018). Carotenoid content of Goji berries: CIELAB, HPLC-DAD analyses and quantitative correlation. Food Chem. 268, 49-56. https//doi.org/10.1016/j.foodchem.2018.06.013.

Radović, M., Milatović, D., Tešić, Ž., Tosti, T., Gašić, U., Dojčinović, B., and Dabić Zagorac, D. (2020). Influence of rootstocks on the chemical composition of the fruits of plum cultivars. J. Food Comp. Anal. 92. https//doi:10.1016/j.jfca.2020.103480.

Rahaman, A., Zeng, X., Kumari, A., Rafiq, M., Siddeeg, A., Manzoor, M.F., Baloch, Z., and Ahmed, Z. (2019). Influence of ultrasoundassisted osmotic dehydration on texture, bioactive compounds and metabolites analysis of plum. Ultrasonics Sonochem. 58. https// doi:10.1016/j.ultsonch.2019.104643.

Rop, O., Jurikova, T., Mlcek, J., Kramarova, D., Sengee, Z., Beceanu, D., and Dommes, D. (2009). Antioxidant activity and selected nutritional values of plums (Prunus domestica L.) typical of the White Carpathian Mountains. Sci. Hortic. 122(4), 545-549. https//doi.org/10.1016/j. scienta.2009.06.036.

Rupasinghe, H.P.V., Jayasankar, S., and Lay, W. (2006). Variation in total phenolics and antioxidant capacity among European plum genotypes. Sci. Hortic. 108(3), 243-246. https//doi.org/10.1016/j. scienta.2006.01.020.

Sahamishirazi, S., Moehring, J., Claupein, W., and Graeff-Hoenninger, S. (2017). Quality assessment of 178 cultivars of plum regarding phenolic, anthocyanin and sugar content. Food Chem. 214, 694-701. https//doi.org/10.1016/j.foodchem.2016.07.070.

Shahab, M., Roberto, S.R., Ahmed, S., Colombo, R.C., Silvestre, J.P., Koyama, R., and De Souza, R.T. (2020). Relationship between anthocyanins and skin color of table grapes treated with abscisic acid at different stages of berry ripening. Sci. Hortic. 259. https//doi. org/10.1016/j.scienta.2019.108859.

Sharma, G. (2003). Digital Color Imaging Handbook (CRC Press). ISBN 0-8493-0900-X.

Siddiq, M., and Sultan, M.T. (2012). Plums and prunes. In Handbook of Fruits and Fruit Processing, N. Sinha, J. Sidhu, J. Barta, J. Wu, and M.P. Cano, eds. (John Wiley Sons Ltd., Blackwell Publishing), p. 551564. ISBN-13: 978-0-8138-0894-9.
Simon-Grao, S., Simon, I., Lidon, V., Conesa, A., Manera, J., Brotons, J.M., Martinez-Nicolas, J.J., and Garcia-Sanchez, F. (2016). Effects of shade screens and mulching on the color change of fruits from 'Fino 49' lemon trees irrigated with water of different salinity or irrigation regimes: Metabolites and main changes during maturation. Sci. Hortic. 209(5), 316-322. https//doi.org/10.1016/j. scienta.2016.06.039.

Tomás-Barberán, F.A., Gil, M.I., Cremin, P., Waterhouse, A.L., HessPierce, B., and Kader, A.A. (2001). HPLC-DAD-ESIMS analysis of phenolic compounds in nectarines, peaches, and plums. J. Agric. Food Chem. 49(10), 4748-4760. https//doi.org/10.1021/jf0104681.

Tomić, J., Štampar, F., Glišić, I., Jakopič, J., Rühmann, S., Neumüller, M., Martinez-Nicolas, J.J., and Garcia-Sanchez, F. (2019). Phytochemical assessment of plum (Prunus domestica L.) cultivars selected in Serbia: Metabolites and main changes during maturation. Food Chem. 299(48), 12011-12019. https//doi.org/10.1016/j. foodchem.2019.125113.

Treutter, D., Wang, D., Farag, M.A., Baires, G.D.A., Rühmann, S., Neumüller, M., Martinez-Nicolas, J.J., and Garcia-Sanchez, F. (2012). Diversity of phenolic profiles in the fruit skin of Prunus domestica plums and related species: Metabolites and main changes during maturation. J. Agric. Food Chem. 60(48), 12011-12019. https//doi. org/10.1021/jf303644f.

Usenik, V., Stampar, F., Veberic, R., Conesa, A., Manera, J., Brotons, J.M., Martinez-Nicolas, J.J., and Garcia-Sanchez, F. (2009). Anthocyanins and fruit colour in plums (Prunus domestica L.) during ripening: Metabolites and main changes during maturation. Food Chem. 114(2), 529-534. https//doi.org/10.1016/j.foodchem.2008.09.083.

Voss, D.H. (1992). Relating colourimeter measurement of plant colour to the royal horticultural society colour chart. HortScience 27(12), 1256-1260.

Xu, C., Zhang, Y., Zhu, L., Huang, Y., and Lu, J. (2011). Influence of growing season on phenolic compounds and antioxidant properties of grape berries from vines grown in subtropical climate. J. Agric. Food Chem. 59(4), 1078-1086. https//doi.org/10.1021/jf104157z.

Received: Jun. 16, 2020

Accepted: Oct. 14, 2020

Addresses of authors:

E. Rampáčková ${ }^{1}$, M. Göttingerová ${ }^{1}$, T. Kiss ${ }^{1}$, I. Ondrášek ${ }^{1}$,

R. Venuta ${ }^{2}$, J. Wolf ${ }^{1}$, T. Nečas ${ }^{1, *}$ and S. Ercisli ${ }^{3}$

${ }^{1}$ Department of Fruit Science, Faculty of Horticulture in

Lednice, Mendel University in Brno, Czech Republic

${ }^{2}$ Fruit Nursery Rostislav Venuta in Kadov, Czech Republic

${ }^{3}$ Department of Horticulture, Ataturk University

Agricultural Faculty, Turkey

*Corresponding author; E-mail: tomas.necas@mendelu.cz 